\title{
Expertise and Collaboration: Cultural Workers' Performance on Social Media
}

\author{
Karen Patel \\ Birmingham City University
}

\section{Introduction}

The idea of the 'expert' is often associated with people who are called upon to provide comment, analysis and critique. In science in particular, experts are the 'voice' in news media about issues of interest to the public (Wynne, 1992). In the arts, the experts are often critics (Bourdieu, 1996; Bennett, 2010) or cultural intermediaries (Taylor, 2013), for example those working in advertising (Nixon, 2014) or consultancy (Prince, 2014). What about experts who aren't critics or intermediaries, i.e. the creators and artists themselves?

I find that expertise is often taken for granted in accounts of cultural work; experts are just experts - they are considered to be more knowledgeable than non-experts, but how? Why? The following quote by Leila Jancovich, in her work on participatory arts programmes, is an example of this:

While some professionals defined their backgrounds as providing invaluable arts expertise, many of the public participants questioned

\section{How to cite this book chapter:}

Patel, K. 2017. Expertise and Collaboration: Cultural workers' performance on social media. In: Graham, J. and Gandini, A. (eds.). Collaborative Production in the Creative Industries. Pp. 157-176. London: University of Westminster Press. DOI: https://doi.org/10.16997/book4.i. License: CC-BY-NC-ND 4.0 
the knowledge of the professionals, referring to them as self-appointed experts. This was supported by the fact that many of the 'experts' interviewed, acknowledged that they knew little about arts practice outside their specialism. (Jancovich, 2015, p. 7)

What exactly makes someone an expert in the arts? Just because someone is less familiar with subjects outside of their field, how does that mean they're not an expert in their specialism, as Jancovic is suggesting?

My analysis of artists' performance of expertise on social media suggests that expertise is a social process, and it is performed on social media in a platformmediated way among artists who negotiate between competition and collaboration. Pierre Bourdieu's The Rules of Art (1996) and Howard Becker's Art Worlds (2008 [1984]) are respectively accounts of competition and collaboration in the art world and both position art-making as a social process, which I argue also helps to conceptualise expertise, too, as a social process.

Social media platforms allow opportunities for cultural workers to find work and build a reputation (Suhr, 2015) but they are also sites for people to perform expertise. Drawing from the empirical work I have carried out on a group of artists I suggest that expertise tends to be performed on social media through the input and endorsement of other people, which contributes to a consensus about someone's expertise and helps to define whether they can be deemed an 'expert'. Ultimately, expertise is important in cultural work because the ability to communicate and demonstrate your expertise is essential in order to secure work (Andres and Round, 2015; Jones, 2002) in a competitive cultural industries job market where there is an 'oversupply of labour' (Banks and Hesmondhalgh, 2009, p. 420).

My empirical work consisted of an analysis of samples of social media posts from 19 independent UK artists working in fine art, digital art, writing, music and crafts. I drew from Candace Jones's (2002) signalling expertise framework for the analysis, to identify particular expertise signalling strategies by the artists. Jones describes signalling as activities which showcase someone's identity through prior projects, competencies and relationships, which 'convey information to others as a form of strategic action' (p. 209). I adapted the framework for the analysis of social media, incorporating elements such as retweets, mentions and imagery used on social media to account for its various affordances which shape how expertise is performed on platforms.

Artists were looked at specifically to explore Bourdieu's (1996) idea of the illusio in relation to arts workers and their performance of expertise on social media, and what this can tell us about contemporary cultural work. The illusio is a 'collective belief in the game' which is 'fundamental to the power of consecration, permitting consecrated artists to constitute certain products, by the miracle of their signature (or brand name) as sacred objects' (p. 230). This consecration is a process involving those in power. What about the illusio in 
the social media age, where any artist can have a public profile, call themselves an expert, and display cultural products which could potentially reach millions of people? From my analysis, there are suggestions that on social media, the status and power of artists' online associations are crucial in their performance of expertise.

While Bourdieu's conception of the art world suggests a competitiveness among artists, Howard Becker's (2008) Art Worlds paints a more collaborative, congenial picture. In my analysis of artists' social media posts I find evidence of this too, where artists would often 'retweet' and help promote the work of fellow artists and craftspeople, who are essentially their competitors. This suggests that expertise is a social process, and artists perform their expertise on social media through a negotiation between competition and collaboration. This builds on current accounts of cultural work, as well as accounts of expertise.

In the following section I'll outline the scholarly work done on expertise, to help us understand how expertise could be most usefully conceptualised.

\section{What is expertise?}

There is no universal definition for what expertise or an expert is, and the notion of the 'expert' is increasingly problematic 'in a world where socially distributed expertise and knowledge production (e.g. peer-to-peer "lay thinking" as facilitated by the internet) is widespread' (Wilson, 2010, p.372). Arnoldi (2007) defines expertise as 'the product of a symbolic attribution of status and authority, changing over time' (p. 50). Schudson (2006) describes an expert as 'someone in possession of specialized knowledge that is accepted by the wider society as legitimate' (p. 499). This echoes Stephen Turner's (2001) view that experts not only need the skills and knowledge, but also recognition from audiences, to be considered expert.

This idea of expertise as socially constituted is apparent in the field of Science and Technology Studies (STS) from which much of the original literature around the philosophy of expertise stems. Scholars in STS sought to investigate the sociology of science, for example Brian Wynne (1992) who highlighted the erosion of public trust in scientific experts and questioned the legitimacy of these experts after the Chernobyl fallout, where the expertise of the 'lay' sheep farmers proved valuable yet was largely ignored by scientists. This questioning of the legitimacy of expertise is discussed by Ulrich Beck (1992) in Risk Society, where public trust in experts was undermined during the 1980s and early 1990s by not only mistakes and inaccuracies, but also the incorrect perception of the public by experts as 'engineering students in their first semester' (p. 59). This led to less public trust in experts, and increased mass media exposure by experts has been argued to contribute to a 
de-legitimisation of expertise overall (Beck, 1998; Luhmann, 2000; Arnoldi, 2007). What about the legitimacy of expertise performed in more contemporary contexts on social media? What form does it take? And how does it link to the context of 'social' interaction where highly collaborative dynamics are at stake? My work in this chapter provides some insights here in relation to artists.

Scholars in STS have tried to unpack exactly what an expert is, with no agreed consensus. Hubert and Stuart Dreyfus (1986) described expertise as an everyday competence and an effective ability to use expert skills and knowledge to improvise in difficult situations - an embodied human performance. Collins and Evans (2006) propose a SEE (Studies of Expertise and Experience) approach, which classifies three types of expertise: no expertise, interactional (experience or practice based) expertise and contributory (knowledge based) expertise. However, the authors admit there are boundary problems with these categorisations, and their conception of experience-based expertise has been criticised by Addis (2013) for placing too much emphasis on the embodied ability of the individual rather than the input and role of others in expertise, using peer review and examination as examples where other people are crucial for expertise.

Following this, expertise is best understood as a social relation, 'where a particular actor has authority over another actor through their possession of a particular form of knowledge: the way a doctor has authority over the patient' (Prince, 2010, p. 6). According to Prince, this results from the expert's situation within a community's knowledge culture. There are parallels here with Pierre Bourdieu's ideas of the illusio.

\section{Expertise in cultural work}

The illusio is applied by Bourdieu in the Rules of Art (1996), where he describes it as a consensus about artists which is fundamental to the elevation of those artists over others. The bourgeoisie in the nineteenth-century art world were influential in this 'elevation' and consecration of artists. Even though such artists would eventually be able to live from just their signature or brand name on their work because they had come to be known as the 'experts' through these power relations, Bourdieu highlights the importance of consensus in the consecration of artists, arguing that the individual, artistic 'genius' is socially constituted and not solely arising from individual talent or special gifts.

Another conceptualisation of the art world comes from Howard Becker (2008) in Art Worlds. Whilst not particularly referring to expertise, Becker highlights the importance of reputation in the art world and how this too is socially constituted. The term 'Art World' is used by Becker: 
To denote the network of people whose cooperative activity, organized via their joint knowledge of conventional means of doing things, produces the kind of art works that the art world is noted for. (p. xxiv)

Art Worlds demonstrates how the influence of others, particularly distributors, critics and consumers, are integral to reputation building. Like Bourdieu, he critiques the myth of the individual, artistic genius and acknowledges the role of people who appear more entitled to speak on behalf of the art world than others. Becker argues that such roles, and subsequent values about how art is to be judged, are formed through a social process where consensus is crucial. In turn, these people are important in the building of an artist's reputation. In a departure from Bourdieu's emphasis on power and power relations, Becker's conception of the production of art places much more emphasis on the division of labour in the process and the amount of collaboration and co-operation involved.

More recent accounts cultural work describe it as precarious (Gill and Pratt, 2008) extremelycompetitive(Bilton,2007) andhighlyindividualised(McGuigan, 2010), but these types of conditions were synonymous with the experiences of artists anyway (Forkert, 2013). What about the experiences of artists in the social media age? The increased popularity of social media platforms in recent years has opened up cultural production to almost everyone who can access it, resulting in a proliferation of 'amateur' cultural production, collaborative co-creative production (Banks, 2009) with subsequent concerns about the inferior quality of cultural products (Keen, 2007) and undermining of professional ethics and values (Kennedy, 2015). Social media too is a competitive space which is increasingly profitable for people who know how to use it for their benefit, whether it be through blogging (Duffy, 2016), selfies on Instagram (Marwick, 2013) or generating Facebook 'likes' (Gerlitz and Helmond, 2013). What about the experiences of artists in this space? What is the role of collaboration here, specifically among artists? This chapter provides insights into how artists utilise social media for the benefit of their career.

There is relatively little work about expertise in contemporary cultural work. Russell Prince (2010) identifies an 'emerging expert system' in the UK creative industries where a small community of people have realigned their practices to situate themselves within government in order to influence cultural policy. However, these people are not cultural workers involved directly in production, but cultural intermediaries (such as critics and consultants) and CEOs of media companies. Candace Jones (2002) draws on the work of Erving Goffman (1959) to conceptualise how expertise is signalled in creative industry careers, arguing that signals are important for conveying one's knowledge and expertise in the competitive creative industries job market. Jones devises a framework for analysing expertise signals, which I adapted for my social media analysis and will discuss in the next section. 


\section{Approach}

To analyse the social media posts of the 19 UK artists, I used a version of Jones' signalling expertise framework (see Patel, 2015) to take into account the specific features of social media, such as platform structures, interactions and affordances. The framework consists of three primary elements, (with my adaptations in brackets): institutional context (i.e. the context of the user, their background and career trajectory), signalling content (the aesthetic style of social media text and images, exhibiting the requisite skills in both their social media posts and presentation of their art, and career relevant connections and interactions on social media) and signalling strategies (using social media affordances such as retweets to enhance status, the type of relationships pursued and how they are manifest on social media, and strategic approaches to impression management on social media). This framework is useful for such an analysis because it specifically focuses on expertise among creative industries workers, however Jones did not test the framework empirically. After amending the framework for social media analysis, the signalling expertise framework becomes a useful tool not only conceptually, but also methodologically.

The 19 artists were found mostly by looking through online artist directories, specifically Arts Derbyshire, Art in Liverpool and New Art West Midlands. I selected artists who appeared to use social media regularly for professional purposes, so for each artist I visited their individual social media profiles and looked at the last time they posted and how frequently they posted. If they had posted at least twice in the past week, I approached them. I also approached artists that I had met at events, or were suggested to me by my own contacts. For each participant, I collected (via screenshot) 10 days' worth of posts from the social media sites they most frequently used; the most common being Twitter, Facebook (pages) and Instagram. The amount of posts collected varied among users, ranging from over 100 posts from one participant to 10 for another so I made some adjustments to the amounts I collected for each participant during the data collection process. Rather than analysing each post individually, I analysed each users' posts in groups of 3 or 4 because I found a lot of posts exhibited similar forms of signalling content. Once all posts were analysed using the signalling content criteria, this helped me work out the user's signalling strategy and institutional context.

\section{Ethical considerations}

In the screenshots that follow in this chapter, you will see that I don't conceal the identity of my participants. All participants mentioned here have given consent for their online identities and social media posts, which includes retweets, to be featured in this discussion. 
The 'publicness' of people's information on the Internet is a primary ethical concern. Even though social media profiles are freely available and people choose to make them public, it doesn't necessarily mean they are 'there for the taking' to be used for research (Henderson et al, 2013). As argued by boyd and Crawford: 'just because it is accessible doesn't make it ethical' (2012: 671). Users may be aware they are using a public forum but some may not fully understand the implications of what they post, or how far it could reach (Marwick and boyd, 2011). For my approach, I decided that being transparent with my participants and asking their permission to use their social media posts was the best option. Allowing them the flexibility to choose which level of anonymity they prefer reduces some of the ethical concerns about the 'publicness' of social media.

Using screenshots is also an unusual practice in social media research, as posts are often extracted through data mining methods (boyd and Crawford, 2012). However that was not suitable for this study, which relies on the close analysis of each individual's posts. In addition, taking screenshots is an effective way of presenting the full context of the post that the platform allows, such as the numbers of retweets and likes for each tweet, Facebook and Instagram likes and comments, and most importantly for artists in particular, the images posted.

\section{Displaying endorsements and positive reviews}

From the analysis, the most prominent theme was the crucial role of other people and institutions in artists' performance of expertise online. This is partly demonstrated in how artists shared endorsements made about them, and also through mutual aid and collaboration within the artistic community, which I will discuss later.

A practice which was most evident on Twitter, most of the artists in my sample used the retweet and 'quote' functions of Twitter to share posts they were mentioned or featured in by others. This particularly centred on their participation in events, but also in direct association to their work. Eimear, a mixed media artist, tweeted first about an exhibition she was participating in:

Eimear Kavanagh @EimearArt·Dec 11

Party tmrw people! Come celebrate with us. Grand re-opening ART \& PASSION roadstudios.co.uk fb.me/4uJRRaTzt

Figure 9.1: Eimear exhibition tweet. 
Then after the show, she retweeted positive comments:

\section{Eimear Kavanagh Retweeted}

Dogstar Rose @Dogstar_3.Dec 13

@road_studios@EimearArt - v impressive exhibition, best i've seen in Liverpool City this year. Delightful bunch of artists and scholars!

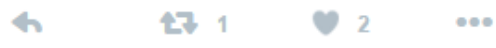

\section{Eimear Kavanagh Retweeted}

niamh kavanagh @hridayayogauk·Dec 13

@EimearArt @road_studios@artinliverpool Well done Amazing visions Good things come 2 those who work hard. Good 2 meet u crazy loveliness's

4 $47 \begin{array}{llll} & 1 & & \end{array}$

Figure 9.2: Eimear retweets.

Robyn, a fine artist, also retweeted mentions about her residency in Wales:

\section{Robyn Woolston Retweeted}

Trust New Art @trustnewart.Dec 8

Fab pics from behind the scenes of @robynwoolston's residency @PenrhynCastleNT@Arts_Wales_. bit.ly/1SCpP2X

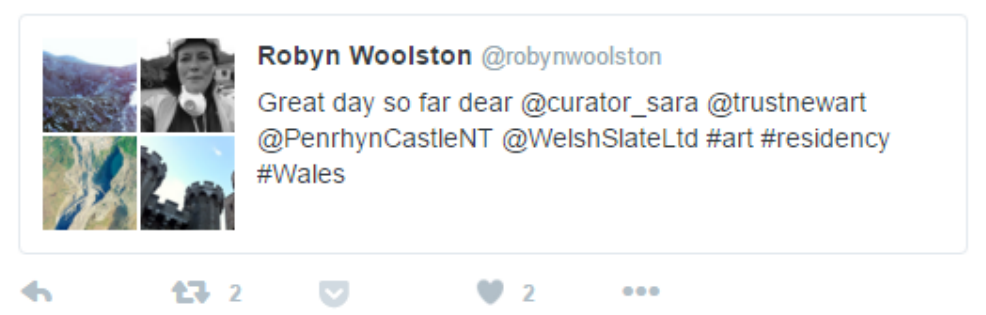

Figure 9.3: Robyn residency tweet.

Robyn also covered this residency extensively by herself on Twitter. These retweets focused on events and exhibitions, and by retweeting the comments and tweets of others, they are adding to coverage of the event on their own Twitter profile, an example of the 'reputation building' signalling strategy in Candace Jones' (2002) signalling expertise framework.

Another form of public endorsement sharing came in the form of 'positive reviews'. For example the below retweet by Colette, an artist in Liverpool: 
colette lilley Retweeted

Michael Borkowsky@MBorkowsky·Dec 6

My 5th \#Perfume \#Portrait is of @sciartists@104DukeStreet artist

@ colettelilley -Just what the doctor ordered! wp.me/p2vnOQ-M7 \#art

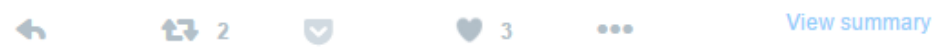

Figure 9.4: Colette retweet.

Not only is this a public endorsement of Colette but also of the art gallery she co-founded. Tweets such as this are a form of 'positive review' which are crucial for people who use social media and other online environments to make a living (Suhr, 2015). Positive reviews were also evident in the Facebook and Instagram comments of Cherie, another artist in Liverpool:
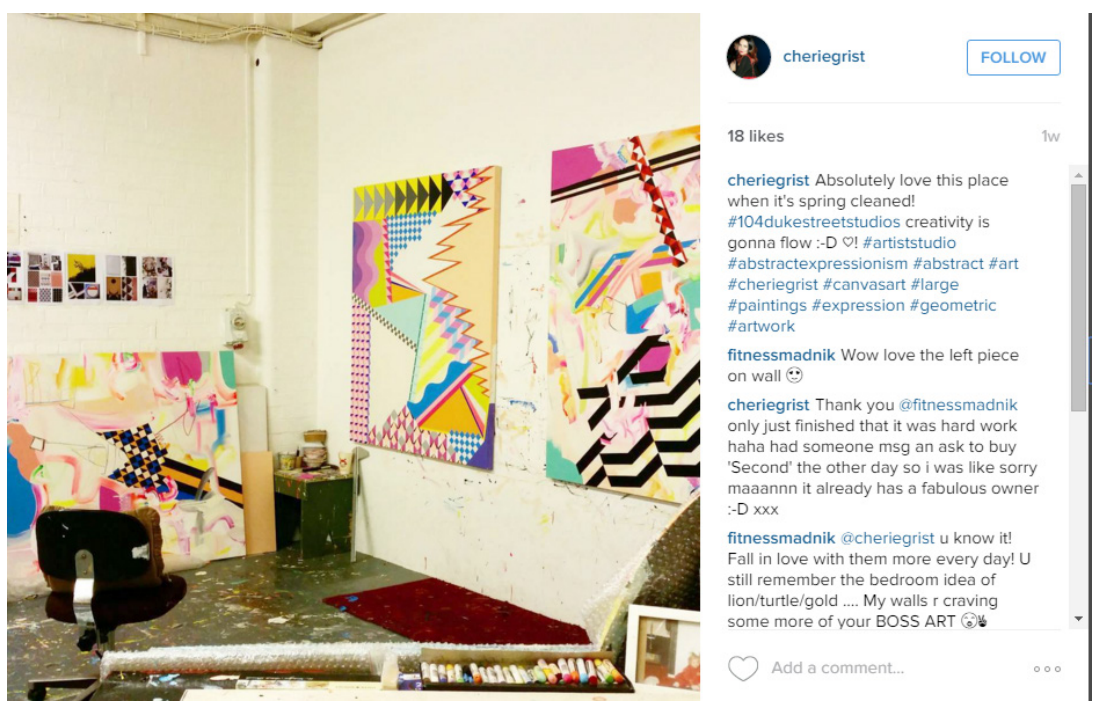

Figure 9.5: Cherie Instagram picture of gallery.

For Cherie, her interaction with customers helped to amplify the positive review, as the user she was speaking to replied with even more positive comments. This is part of what Jones (2002) calls an 'impression management' signalling strategy.

The most important form of public endorsement for an artist would come from a high profile individual or institution, and there were a couple of examples among the artists of this endorsement being amplified by them. Being 
associated with or acknowledged by higher profile individuals and companies is important for one's career, and this is illustrated by Bourdieu's idea of the illusio. Bourdieu talks about how powerful individuals were able to elevate and consecrate some artists over others, through a social process of consensus. That, to some extent is still the case because the more renowned an endorser is, the more power they have to elevate an artist over others on social media. A high profile individual or institution can show endorsement simply by tweeting about that artist and their work, and this is what I understand as a public endorsement. In the case of the artists within my sample, two in particular, Abi and Phil, displayed the endorsement of high profile companies. Abi, an artist and author, was mentioned by her publisher, which she retweeted and added a comment:

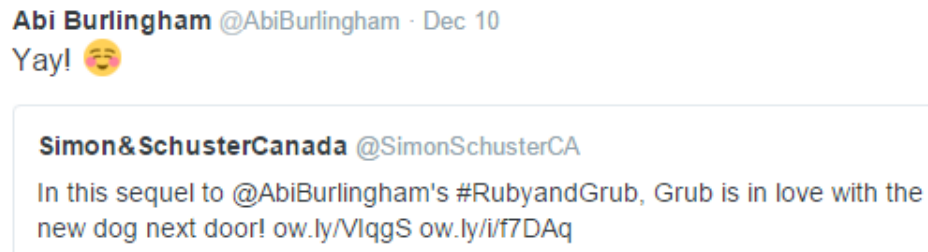

Figure 9.6: Abi quote of publisher.

Phil, a music composer, often tweeted about his work and where it is featured:

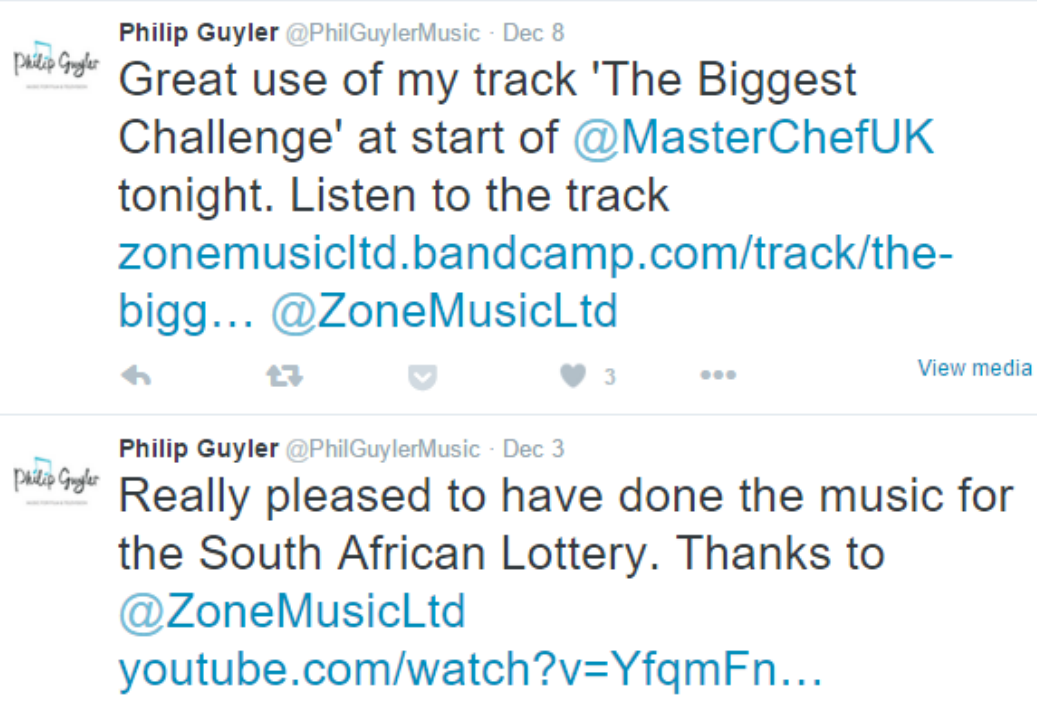

Figure 9.7: Phil's tweets about his work. 
While Phil didn't retweet, he mentioned those organisations in his tweets to associate himself with them. Using mentions in tweets about higher profile work is an example of the 'amplification' of signals as part of the 'status enhancement' element of signalling expertise. The specific functions of Twitter such as mentions and retweets allow this amplification to occur in a public way with just a click.

Not everyone within the sample associated with others in the ways described here, for example Colin, who rarely retweeted others and posted only his own work on Facebook, Twitter and Instagram, sometimes with an offer to buy prints or a discount code. Compared to the other participants, he appeared to have the highest profile, with thousands of followers across all platforms and hundreds of likes for each post. He appeared to have less of a need to share the endorsements of others.

These acts of retweeting and sharing are most common with Twitter, because the platform structure allows it. Only when posts are created by the user, such as in the case of Cherie who took her photo and put it on Instagram, can the associations occur through other means such as likes and comments. This demonstrates how the functions of the platform can be fundamental to how expertise is performed on social media.

So, while the illusio can help us to understand the importance of influential people and institutions in artists' performance of expertise, the analysis revealed an activity which problematises Bourdieu's conception of the competitive, individualistic art world, and this was expressed through mutual aid and collaboration within the artistic community.

\section{'Mutual aid' and collaboration among the artistic community}

'Mutual aid' is a concept applied to the cultural industries by de Peuter and Cohen (2015) to describe the development of 'bottom-up infrastructures to support independent work' $(2015$, p. 306) in the context of worker resistance in the cultural industries, 'where workers, often through new labour organizations that exist outside the bounds of traditional trade unions, are lobbying for social protections and higher pay and exerting collective pressure to reclaim autonomy over their crafts and their lives' (2015, p. 305). While their specific example doesn't relate directly to this work, the idea of mutual aid is useful to describe the displays of mutual support among the artistic community, visible on social media, in contemporary cultural work where discourses of individualism and enterprise prevail in a precarious labour market.

Mutual aid is used by de Peuter and Cohen to describe the collaboration between cultural workers to improve labour conditions. By working together, cultural workers have increased powers for collective bargaining. For this research, the idea of artists collaborating and working towards a common goal is a useful way of conceptualising the activities of the artists I observed. In my analysis, I found numerous examples of artists sharing the work of other 
artists, even those who appeared to be in direct competition with them. Why would they do this? The concept of mutual aid helps us understand that such collaboration brings benefits to all artists involved, and as I'll demonstrate in this section, on social media these benefits include more exposure for their work and the formation of mutually beneficial associations, which both contribute to the artists' performance of expertise.

This type of activity among artists is evident in Howard Becker's (2008) account of the art world, which describes artists as supportive and collaborative rather than competitive. Becker, importantly, also describes the role of 'folk' art done by 'ordinary people in the course of their ordinary lives, work seldom thought of by those who make or use it as art at all, even though, as often happens, others from outside the community it is produced in find artistic value in it' (2008, p. 246). He illustrates this with the example of women quilt makers, who make them as family members and neighbours, not as artists. These types of activities can now be monetised through social media and websites such as Etsy, where a particular 'handmade' community has formed which has contributed to the revival of craft work (Luckman, 2015). Some of the participants I observed make and sell their work through Etsy, and it was within this group that I found many examples of retweeting and sharing other artists' work-artists they are also in competition with. Below, Abi sells her own art through Etsy and yet she regularly retweets the work of other makers, often with a positive comment:

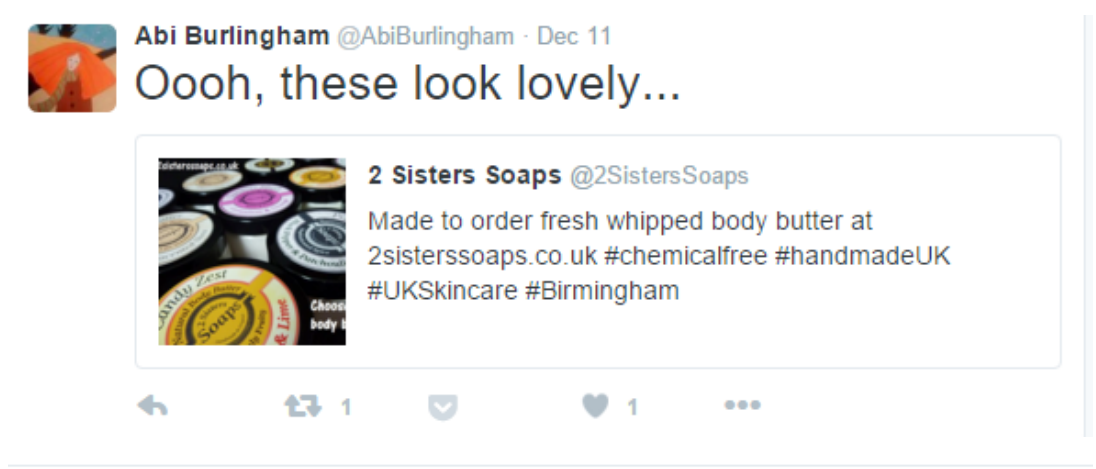

Abi Burlingham AbiBurlingham - Dec 12

Awww, so cute 6

SweetPicklesDesigns @SweetPicklesD

These are so cute!

By Beardbangs on Etsy

etsy.me/1k2bv88 fb.me/5TEq1Sz19

Figures 9.8a, b: Abi retweets of crafts. 
Lisa, a writer, often praised work of other writers:

Lisa Shambrook@LisaShambrook ·Jan 15

Just finished All The What Ifs by

(a) ang_writes ....if you want an authentic and beautifully written \#YA This is it! amazon.co.uk/All-What-Ifs-A...

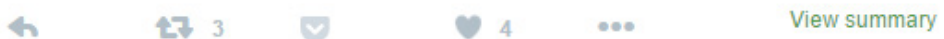

Lisa Shambrook@LisaShambrook ·Jan 15

Read first story@PatriciaParis1 made me giggle \& relax before dentist \& filling! amazon.co.uk/Winters-Romanc... \#romance

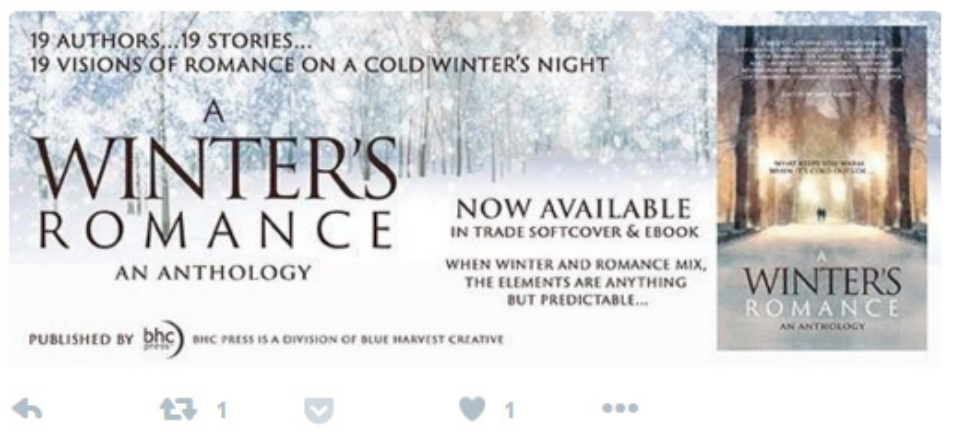

Figure 9.9: Lisa: supportive tweets.

The second tweet features an anthology called A Winter's Romance, which includes a story by Lisa. Yet, she is tweeting about this anthology not by mentioning her own work, but the contribution of another writer in the anthology by posting a mini positive review.

Lisa and Abi appear to be retweeting the work of people who are essentially their competitors; they are helping to promote their competitors' work by sharing it on their own Twitter profile. This is an example of reciprocity, which is a common practice on social media as a form of mutually beneficial online social relation (Chia, 2012) driven by the idea that people will eventually be rewarded for their own engagement. In Abi's case, her reward for retweeting others' work is an enhancement of her own profile by telling her followers a little more about herself, through the work of others. Lisa in particular was involved in a collaboration with other writers which seemed mutually beneficial for all, because by mentioning fellow writers in the anthology it increases the chances of them returning the favour either immediately or at another point in the future. This reciprocity is a collaborative mechanism that reinforces the artists' performance of expertise on social media, and would be more effective for reaching 
more people than an artist simply posting their own work, without interacting with others. While these artists are sharing the work of their competitors, the benefits of collaboration outweigh the potential threat from competition.

There were other forms of mutual aid and collaboration also in evidence on social media. Maria, a textiles artist, tweeted an open call and publicly mentioned it to two other artists who she felt may be interested; an altruistic act and an example of artists supporting each other.

These acts of endorsement and 'mutual aid' on social media potentially problematise the notions of individualistic, competitive artistic work described by Bourdieu (1996) and repeated in subsequent accounts of cultural work in neoliberal times, for example by Jen Harvie (2013), who describes the 'artpreneur', working 'privately for her own advantage, she models neoliberalism' (p. 63). Such discourses of individualism, competitiveness, workaholism and blurring between personal and professional life are well documented in cultural work (see Hesmondhalgh and Baker, 2011) with Melissa Gregg (2014) highlighting how this is exacerbated by new technologies. Alice Marwick (2013) argued that social media applications foster an individualistic subjectivity and encourage competition, but my findings suggest this isn't necessarily the case for these artists.

For them, social media platforms allow new opportunities for work, collaboration and mutual aid among both 'professional' and 'amateur' artists. The platform-specific features within Twitter allow these artists to share each other's work, with positive comments through the 'quote' function (as Abi did) or by including other artists in posts through @ mentions. Where there is collaboration between artists, as with Lisa and the anthology, she posted and commented on the work of others within that anthology as a way of simultaneously promoting her work and that of the other writers, reinforcing the possibility of reciprocal re-posting and retweeting to further amplify and increase the potential audience for the work. This mutual aid on social media is also a part of the collaboration.

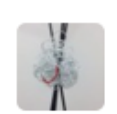

maria walker @blueberrybutton. Dec 14

Exciting open call for forthcoming Exhib- check it out@GreenslateJane (a) AnnaFCSmith

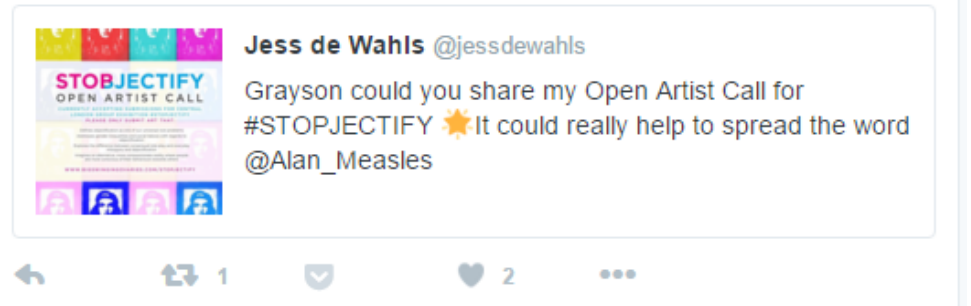

Figure 9.10: Maria sharing opportunity retweet. 
Within my sample, these acts of mutual aid and support were displayed most frequently among the female participants, and between them and fellow female artists. Susan Luckman (2015) notes the resurgence in the 'craft economy' particularly among middle class women, who choose to work from home and set up craft businesses on Etsy which fit around the demands of parental and domestic responsibilities. While Luckman usefully highlights the isolation and stress these women face, who juggle managing their businesses, their identities (particularly online) and their families, she does not pay much attention to the possibilities offered by running these online businesses, and the potentially positive social connections formed between female makers and artists which can be facilitated through social media and sites such as Etsy. Further research could examine this in more depth, by interviewing female artists in relation to how they use social media, particularly in terms of collaboration and mutual aid.

\section{Conclusion}

The aim of this chapter was to find out how expertise is performed on social media by artists, and what this means for collaboration in cultural work. I tested the applicability of Pierre Bourdieu's illusio, a concept which suggests that in the art world, positive consensus about an artists' expertise is crucial for that artist to be consecrated, or elevated, among others. I aimed to work through this concept on social media interactions and posts by artists, as part of their performance of expertise, because the idea of the illusio is a competitive, individualistic conception of the art world, compared to more collaborative accounts such as Howard Becker's Art Worlds.

Through my analysis, I found evidence of both competition and collaboration in artists' performance of expertise on social media. The illusio highlights the role of powerful people and organisations in elevating artists to prominence. If artists are associated with well-known people or companies on social media, that potentially increases their exposure, elevates their status and significantly enhances their performance of expertise. Also important for these artists are positive reviews from customers, clients and peers, which are regularly retweeted and shared. This builds on work about online evaluation (Reagle, 2015; Gandini, 2015) and I suggest this is a more specific type of evaluation, because on sites such as Twitter and Facebook such positive or negative reviews can be carefully curated by the artist, who can choose whether or not to share it to their own profile.

I conceptualised evidence of collaboration using the idea of mutual aid (de Peuter and Cohen, 2015). On social media, this was apparent through artists' retweeting and sharing of each other's work on social media, even though they are potential competitors for work. This appears to be a more congenial, altruistic practice, what Howard Becker described in Art Worlds - where 
collaboration is essential for artists to create and sell their work. Mutual aid is a useful concept to describe cultural workers helping each other in this way. What also needs to be considered on social media are some of the particular norms of social relation, such as reciprocity, where users participate with some expectation of receiving some form of return or reward for their engagement.

An effective performance of expertise is what enables artists to gain work and make a living, and social media platforms are a relatively free and potentially wide-reaching way to do this. From my analysis, I argue that the artists using social media for the performance of expertise negotiate between promoting their own work, and forming potentially beneficial online associations with other artists in their area. While associating with high-profile companies and people is important for artists' performance of expertise, collaboration is equally crucial too, because the associations formed with other artists can lead to increased exposure of each other's work on social media through reciprocal sharing and mutual aid. I also found evidence of mutually beneficial collaborative production in the anthology Lisa was involved in. This collaboration enabled Lisa to promote her anthology by posting and commenting on the contributions of others.

The evidence of collaboration and mutual aid in my analysis also offers a departure from more individualistic conceptions of social media activity, particularly self-branding (Hearn, 2008; Page, 2012; Marwick, 2013) and self-promotion (Scharff, 2015). Such ideas imply an inward-looking and self-centred approach to social media performance, and while of course the artists in my sample are performing expertise for their own benefit, they are often raising the profile of other artists at the same time.

A final consideration is the role of social media platforms in these practices of performing expertise. It is important to remember that social media platforms have particular temporal and structural qualities which affect the way people use them, and how information is received from them. Ultimately, these platforms are designed to harvest people's information to make money (Andrejevic, 2011; Arvidsson and Colleoni, 2012). Skeggs and Yuill (2015) argue that platforms and the algorithms that run them are ideological; they are structured in certain ways and can be changed by developers at any time to continue to serve the interests of owners and corporations.

These corporations and their platforms shape the way that expertise is performed on social media, and the way it is received by users. Artists in my study negotiate this as part of their work, and I argue that platforms are crucial to consider in contemporary accounts of cultural work. Artists need to get their work noticed in order to sell their work, get commissions and make a living. Social media is a relatively cheap way for artists to perform their expertise and get their work noticed, and platforms for some of them are central to this. Sometimes, this is done through collaborations, and these collaborations can be facilitated through the Internet and particularly social media, an efficient 
way to network and connect with fellow artists all around the world and participate in collaborative projects often from the comfort of their own home. Corporation-owned platforms, then, are central to this, and the algorithms and platform structures mediate collaborations and performances of expertise, ultimately, to benefit the corporations. User data is sold to marketing companies, platforms are designed to deliver advertisements, and the users themselves need to agree to terms and conditions in order to continue benefitting from the 'free' platforms. How do artists negotiate these trade-offs? The corporations ultimately benefit, but most of the artists in my sample also benefit from platforms, so does that make it okay? Any future research which involves social media should be more critical of platforms and platform owners.

While this chapter provides some important insights into contemporary cultural work, collaboration, expertise and social media methods, further work is required to explore the experience of female artists in particular in relation to collaboration and the performance of expertise, and how expertise is performed on social media by people working in other competitive sectors, drawing from the methods utilised in this chapter.

\section{References}

Addis, M. (2013). Linguistic competence and expertise. Phenomenology and the Cognitive Sciences, 12 (July 2013): 327-36. DOI: https://doi.org/ 10.1007/ s11097-011-9211-5

Andrejevic, M. (2011). The work that affective economics does. Cultural Studies, 25(4-5): 604-20. DOI: https://doi.org/10.1080/09502386.2011.6 00551.

Andres, L., \& Round, J. (2015). The creative economy in a context of transition: A review of the mechanisms of micro-resilience. Cities, 45: 1-6. DOI: https://doi.org/10.1016/j.cities.2015.02.003.

Arnoldi, J. (2007). Universities and the public recognition of expertise. Minerva, 45(1): 49-61. DOI: https://doi.org/10.1007/s11024-006-9028-5.

Arvidsson, A., \& Colleoni, E. (2012). Value in informational capitalism and on the Internet. The Information Society, 28(3): 135-50. DOI: 10.1080/01972243.2012.669449.

Banks, J. (2009). Co-creative expertise: Auran Games and Fury - A case study. Media International Australia, 130, 77-89. DOI: https://doi.org/10.1177/1329 878X0913000110.

Banks, M., \& Hesmondhalgh, D. (2009). Looking for work in creative industries policy. International Journal of Cultural Policy, 15(4): 415-30. DOI: https://doi.org/10.1080/10286630902923323.

Beck, U. (1992). Risk Society: Towards a New Modernity. London: SAGE. . (1998). Politics of Risk Society. In Politics of Risk Society, J. Franklin (Ed.). Cambridge: Polity. 
Becker, H. (2008). Art Worlds 25th Anniversary edition. Berkeley, CA: University of California Press.

Bennett, T. (2010). Sociology, aesthetics, expertise. New Literary History, 41(2): 253-76.

Bilton, C. (2007). Management and Creativity: From Creative Industries to Creative Management. Oxford: Blackwell Publishing.

Bourdieu, P. (1996). The Rules of Art: Genesis and Structure of the Literary Field, translated from French by S. Emanuel. Cambridge: Polity Press.

boyd, D., \& Crawford, K. (2012). Critical questions for Big Data. Information, Communication \& Society, 15(5): 662-79. DOI: https://doi.org/10.1080/1 369118X.2012.678878.

Chia, A. (2012). Welcome to me-mart: The politics of user-generated content in personal blogs. American Behavioral Scientist, 56(4): 421-38. DOI: https:// doi.org/10.1177/0002764211429359.

Collins, H.M. and Evans, R. (2002). The third wave of science studies: Studies of expertise and experience. Social Studies of Science, 32(2): 235-96. DOI: https://doi.org/10.1177/0306312702032002003.

de Peuter, G., \& Cohen, N. S. (2015). Emerging Labour Politics in Creative Industries. In K. Oakley \& J. O’Connor, (Eds.) The Routledge Companion to the Cultural Industries. London: Routledge, pp. 305-18.

Dreyfus, H. L., \& Dreyfus, S. E. (1986). From Socrates to Expert Systems: The Limits of Calculative Rationality. Technology in Society Vol. 6(3): 217-233

Duffy, B. E. (2016). The romance of work: Gender and aspirational labour in the digital culture industries. International Journal of Cultural Studies 19(4): 441-57. DOI: https://doi.org/10.1177/1367877915572186.

Forkert, K. (2013). Artistic Lives: A Study of Creativity in Two European Cities. Farnham: Ashgate Publishing.

Gandini, A. (2015). Online social influence and the evaluation of creative practice: A critique of klout. In H.C. Suhr (Eds.) Online Evaluation of Creativity and the Arts. London: Routledge, pp. 150-68.

Gerlitz, C., \& Helmond, A. (2013). The Like Economy: Social buttons and the data-intensive web. New Media \& Society, 15(8): 1348-65. DOI: https://doi. org/10.1177/1461444812472322

Gill, R., \& Pratt, A. (2008). In the social factory? Immaterial labour, precariousness and cultural work. Theory, Culture \& Society, 25(7-8): 1-30. DOI: https://doi.org/10.1177/0263276408097794.

Goffman, E. (1959). The Presentation of Self in Everyday Life. New York, NY: Doubleday.

Gregg, M. (2014). Presence Bleed: Performing Professionalism Online. In M. Banks, R. Gill and S. Taylor, (Eds.) Theorizing Cultural Work: Labour, Continuity and Change in the Cultural and Creative Industries. London: Routledge, pp. 122-35.

Harvie, J. (2013). Fair Play: Art, Performance and Neoliberalism. Basingstoke: Palgrave Macmillan. 
Hearn, A. (2008). 'Meat, Mask, Burden': Probing the contours of the branded 'self'. Journal of Consumer Culture, 8(2), 197-217. DOI: https://doi. org/10.1177/1469540508090086

Henderson, M., Johnson, N. F., \& Auld, G. (2013). Silences of ethical practice: Dilemmas for researchers using social media. Educational Research and Evaluation, 19(6): 546-60. DOI: https://doi.org/10.1080/13803611.2013.805656.

Hesmondhalgh, D., \& Baker, S. (2011). Creative Labour: Media Work in Three Cultural Industries. London: Routledge.

Jancovich, L. (2015). The participation myth. International Journal of Cultural Policy, (May 2015): 1-15. DOI: https://doi.org/10.1080/10286632.2015.10 27698.

Jones, C. (2002). Signaling expertise: How signals shape careers in creative industries. In M. Peiperl, M. Bernard \& A. Anand, (Eds.) Career Creativity: Explorations in the Remaking of Work. Oxford: Oxford University Press, pp. 209-28.

Keen, A. (2007). The Cult of the Amateur: How Blogs, MySpace, YouTube, and The Rest of Today's User-generated Media Are Destroying Our Economy, Our Culture, and Our Values. London: Nicholas Brealey Publishing.

Kennedy, H. (2015) No Learning, No Spec: Spec Work Competitions and the Spec Movement. In H.C. Suhr (Eds.) Online Evaluation of Creativity and the Arts. London: Routledge, pp. 112-28.

Luckman, S. (2015). Craft and the Creative Economy. Basingstoke: Palgrave Macmillan.

Luhmann N. (2000). Art as a Social System. Stanford, CA: Stanford University Press.

Marwick, A. E., \& boyd, D. (2011). I Tweet Honestly, I Tweet Passionately: Twitter Users, Context Collapse, and the Imagined Audience. New Media \& Society, 13 (1): 114-33. DOI: https://doi.org/10.1177/1461444810365313.

Marwick, A. E. (2013). Status Update: Celebrity, Publicity, and Branding in the Social Media Age. New Haven, CT: Yale University Press.

McGuigan, J. (2010). Creative labour, cultural work and individualisation. International Journal of Cultural Policy, 16 (3): 323-35. DOI: https://doi. org/10.1080/10286630903029658.

Nixon, S. (2014). Cultural intermediaries or market device? The case of advertising. In J.S. Maguire and J. Matthews, (Eds.) The Cultural Intermediaries Reader. London: SAGE, pp. 34-42.

Page, R. (2012) The linguistics of self-branding and micro-celebrity in Twitter: The role of hashtags. Discourse \& Communication, 6(2): 181-201. DOI: https://doi.org/10.1177/1750481312437441.

Patel, K. (2015) The performance of expertise on social media by creative and cultural workers. Presented 19 June at Reframing Media/Cultural Studies, University of Westminster. Retrieved from https://www.academia. edu/18642850/The_Performance_of_Expertise_on_Social_Media_by_ Creative_and_Cultural_Workers._Cultures_in_Disarray_Kings_College_ 
London_11_Jun_2015_and_Reframing_Media_Cultural_Studies_ University_of_Westminster_19_Jun_2015.

Prince, R. (2010). 'Fleshing out' expertise: The making of creative industries experts in the United Kingdom, Geoforum, 41(6): 875-84.

. (2014). Economies of Expertise: Consultants and the Assemblage of Culture. Journal of Cultural Economy (ahead of print): 1-15. DOI: https://doi. org/10.1080/17530350.2014.974654.

Reagle, J. (2015) Revenge Rating and Tweak Critique at Photo.net. In H.C. Suhr (Ed.) Online Evaluation of Creativity and the Arts. New York, NY: Routledge, pp. 20-40.

Scharff, C. (2015). Blowing your own trumpet: Exploring the gendered dynamics of self-promotion in the classical music profession. The Sociological Review, 63(S1): 97-112. DOI: https://doi.org/10.1111/1467-954X.12243.

Schudson, M. (2006). The trouble with experts-and why democracies need them. Theory and Society, 35 (5-6): 491-506. DOI: https://doi.org/10.1007/ s11186-006-9012-y.

Skeggs, B., \& Yuill, S. (2015). The methodology of a multi-model project examining how Facebook infrastructures social relations. Information, Communication \& Society, 4462(October): 1-17. DOI: https://doi.org/10.1080/13691 18X.2015.1091026.

Suhr, H.C. (2015) Introduction: Toward an Interdisciplinary Understanding of Online Evaluation of Creativity and the Arts. In H.C. Suhr (Ed.) Online Evaluation of Creativity and the Arts. New York, NY: Routledge, pp. 1-19.

Taylor, C. (2013). Between culture, policy and industry: modalities of intermediation in the creative economy. Regional Studies, (November 2014): 1-12. DOI: https://doi.org/10.1080/00343404.2012.748981.

Turner, S. (2001). What is the problem with experts? Social Studies of Science, 31(1): 123-49. DOI: https://doi.org/10.1177/030631201031001007

Wilson, N. (2010). Social creativity: Re-qualifying the creative economy. International Journal of Cultural Policy, 16(3): 367-81. DOI: https://doi. org/10.1080/10286630903111621.

Wynne, B. (1992). Misunderstood misunderstandings: Social identities and public uptake of science. Public Understanding of Science, (1): 281-304. DOI: https://doi.org/10.1088/0963-6625/1/3/004. 